\title{
An Exemplary Model Study for Overcoming Stuck Fermentation during Spontaneous Fermentation with the Aid of a Saccharomyces Triple Hybrid
}

\author{
Eva Christ ${ }^{1}$, Matthias Kowalczyk ${ }^{1}$, Magdalena Zuchowska ${ }^{1}$, Harald Claus ${ }^{1}$, Reinhard Löwenstein ${ }^{2}$, Aleksandra \\ Szopinska-Morawska ${ }^{3}$, Jenny Renaut ${ }^{3} \&$ Helmut König ${ }^{1}$ \\ ${ }^{1}$ Institute of Microbiology and Wine Research, Johannes Gutenberg University Mainz, Mainz, Germany \\ ${ }^{2}$ Winery Heymann-Löwenstein, Winningen, Germany \\ ${ }^{3}$ Centre de Recherche Public, Gabriel Lippmann, Belvaux, Luxemburg \\ Correspondence: Eva Christ, Institute of Microbiology and Wine Research, Johannes Gutenberg University \\ Mainz, Johann-Joachim-Becherweg 15, 55128 Mainz, Germany. E-mail: christe@uni-mainz.de
}

Received: March 22, 2015 Accepted: May 19, 2015 Online Published: July 15, 2015

doi:10.5539/jas.v7n8p18 URL: http://dx.doi.org/10.5539/jas.v7n8p18

\begin{abstract}
Sluggish or stuck fermentations cause significant financial losses for winemakers each year. In order to investigate the reasons for problems during spontaneous fermentation of Riesling must in a well-known German vineyard of the lower Moselle, yeast strains involved in must fermentation were identified during winemaking in the two years 2011 and 2012. Identification of the yeast isolates was performed by applying analyses of the ITS-1-5.8-ITS2 region and restriction fragment analyses of different gene sequences. It revealed that Saccharomyces (S.) bayanus and not Saccharomyces cerevisiae was the main fermenting yeast. Either S. bayanus finished the fermentation or led to stuck fermentation. After about four weeks of stuck, fermentation continued spontaneously $S$. bayanus was replaced by the triple hybrid $S$. cerevisiae $\times$ S. kudriavzevii $\times$ S. bayanus. The triple hybrid strain HL 78 was able to utilize fructose more efficiently than $S$. bayanus strain HL 77 . The fructophilic character of the triple hybrid strain correlated with an enhanced uptake of radiolabeled fructose compared to glucose.

In contrast to the usual starter culture $S$. cerevisiae, both isolates, S. bayanus strain HL 77 and the triple hybrid strain HL 78, could grow in the absence of ammonium when amino acids were present. However, the triple hybrid was able to consume glucose and especially fructose at lower amino acid concentrations. Thus, the triple hybrid strain HL 78 was a suitable strain to overcome stuck fermentation without changing the fermentation conditions and the aroma profile desired by the selected winery. It has already been successfully used to restart stuck fermentation. The procedure described here could be a useful approach for wine makers facing problems during spontaneous fermentation. Since the application of genetically modified yeast strains is not allowed for starter culture, based on these studies we suggest the generation of hybrid strains with desired phenotypical features from mother yeasts strains/species of a certain winery and their application in case that during a spontaneous fermentations a sluggish or stuck fermentation is observed.
\end{abstract}

Keywords: spontaneous fermentation, stuck fermentation, Saccharomyces, hybrid yeasts, RFLP analysis, ammonium requirement

\section{Introduction}

Despite the advantages of starter cultures, some winegrowers prefer a spontaneous fermentation to produce wines of high quality with a distinctive and characteristic sensory profile. However, the risk of stuck fermentation increases with the application of spontaneous fermentation, as these microbial processes rely on the complex indigenous microbiota of the grapes and the winery. A stuck fermentation is characterized by a higher than desired residual sugar content at the end of the fermentation, while a sluggish fermentation shows retarded sugar consumption by the fermenting microbes (Bisson, 1999). The most important and well-known natural yeast in spontaneous fermentations is Saccharomyces cerevisiae, although Saccharomyces bayanus may also be found in the later stages of fermentations (Ultee et al., 2013). However, hybrids of Saccharomyces species have also been identified as being involved in the fermentation process during winemaking (González et al., 2006; 
Arroyo-López et al., 2009; Blättel et al., 2013). González et al. (2006) described the hybrid S. cerevisiae $\times$ S. kudriavzevii which could be advantageous for specific fermentation conditions due to the combined characteristics of both parents. The hybrid was noted to be tolerant against high ethanol concentration and osmolarity as exhibited by $S$. cerevisiae and tolerant against cool temperatures as a feature of $S$. kudriavzevii. Several authors have isolated this type of hybrid in Europe (Bradbury et al., 2006; González et al., 2008; Lopes et al., 2010), although the strains of $S$. kudriavzevii known so far have been isolated from decaying leaves in Japan (Naumov et al., 2000) and from oak bark samples in Portugal (Sampaio \& Gonçalves, 2008), but not yet from grapes or must.

The aims of this study were to achieve a deeper understanding of the microbiology of spontaneous fermentation and to find novel ways to avoid or overcome sluggish or stuck fermentations caused by wine yeasts. In order to investigate the reasons for sluggish or stuck fermentations, the succession of yeast populations during spontaneous fermentations in a German winery in the lower Moselle (Terraces Moselle) winegrowing region was studied. In this paper we concentrate on the succession and culture profile of the identified Saccharomyces strains.

\section{Method}

\subsection{Organisms}

Several yeast strains of the genus Saccharomyces were used as references for the identification of isolated hybrid strains via restriction fragment length polymorphism (RFLP) analysis (Table 1).

Table 1. Saccharomyces strains used in this study

\begin{tabular}{lll}
\hline Species & Strain & Origin \\
\hline Saccharomyces bayanus & DSM 70412 & DSMZ \\
Saccharomyces cerevisiae & DSM 70449 & DSMZ \\
Saccharomyces cerevisiae & Fermivin ${ }^{\mathrm{T}}$ & DSM Food Specialties \\
Saccharomyces kudriavzevii & CBS $8840^{\mathrm{T}}$ & CBS \\
Saccharomyces paradoxus & CBS $432^{\mathrm{T}}$ & $\mathrm{CBS}$ \\
S. bayanus & HL 77 & IMW \\
S. cerevisiae $\times$ S. kudriavzevii $\times$ S. bayanus & HL 78 & IMW \\
S. cerevisiae $x$ S. kudriavzevii $\times S$. bayanus & 82.14 & IMW \\
S. cerevisiae $\times$ S. kudriavzevii $\times$ S. bayanus & 96.1 & IMW
\end{tabular}

Note. CBS: Centraalbureau voor Schimmelcultures, Utrecht, The Netherlands; DSMZ: Deutsche Sammlung von Mikroorganismen und Zellkulturen, Braunschweig, Germany; IMW: Institute for Microbiology and Wine Research, Johannes Gutenberg University Mainz, Germany; ${ }^{\mathrm{T}}$ : type strain.

1) Strains HL 77, HL 78, 82.14 and 96.1 were isolated during the study.

\subsection{Sampling and Cultivation}

The sampling of fermenting must of the Riesling grape variety from the Heymann-Löwenstein winery in the lower Moselle (Winningen, Germany) took place at regular intervals of two weeks during the fermentation periods from September to January in 2011 and 2012 (Table 2). Steel and wooden wine barrels were sampled. The barrels had a capacity of 2,500 L and they were filled up to the maximum and kept at room temperature. Sample volumes of $50 \mathrm{~mL}$ were collected every two weeks in general. 
Table 2. Casks sampled in a German winery in the lower Moselle ${ }^{1)}$

\begin{tabular}{lllll}
\hline Cask number & Vintage & Material & Stuck fermentation & Parameters tested \\
\hline 1 & 2011 & steel & No & microbial and chemical \\
2 & 2011 & wooden & Yes & microbial and chemical \\
3 & 2011 & wooden & Yes & chemical \\
4 & 2011 & wooden & Yes & chemical \\
5 & 2011 & wooden & Yes & chemical \\
6 & 2012 & steel & Yes & microbial and chemical \\
\hline
\end{tabular}

Note. ${ }^{1}$ Casks were tested for microbial succession and/or sugar contents.

The yeasts were isolated by plating, using different culture media which include: GPYA (glucose peptone yeast extract agar comprising g/L: glucose 40.0, peptone 5.0, yeast extract 5.0, agar 15.0), PDA (potato dextrose agar $\mathrm{g} / \mathrm{L}$ : potato dextrose bouillon 26.5 [Roth, Karlsruhe, Germany], agar 12.0) and GYP (glucose yeast extract peptone agar g/L: yeast extract 10.0, glucose 20.0, peptone 20.0, agar 15.0). All media were adjusted to $1 \mathrm{~L}$ with deionized water.

Modified B-medium (Heerde \& Radler, 1978) was used for growth experiments: glucose $25.0 \mathrm{~g}$, fructose $25.0 \mathrm{~g}$, malate $20.0 \mathrm{~g},\left(\mathrm{NH}_{4}\right)_{2} \mathrm{SO}_{4} 1.5 \mathrm{~g}, \mathrm{MgSO}_{4} \cdot 7 \mathrm{H}_{2} \mathrm{O} 1.0 \mathrm{~g}$, sodium citrate $0.5 \mathrm{~g}$, inositol $40.0 \mathrm{mg}$, amino acid solution (L-alanine $0.75 \mathrm{~g}$, L-arginine $3.5 \mathrm{~g}$, L-histidine $0.2 \mathrm{~g}$, L-methionine $0.4 \mathrm{~g}$, L-serine $0.5 \mathrm{~g}$, L-threonine $2.0 \mathrm{~g}$, L-tryptophane $0.4 \mathrm{~g}$, L-aspartic acid $0.5 \mathrm{~g}$, L-glutamic acid $3.0 \mathrm{~g}$, adjusted to $1 \mathrm{~L}$ with deionized water) $100 \mathrm{~mL}$, vitamin solution $10 \mathrm{~mL}$, and trace mineral solution $10 \mathrm{~mL}$, adjusted to $1 \mathrm{~L}$ with deionized water, $\mathrm{pH} 3.3$. Four quadruplicate growth experiments were performed in parallel for each yeast strain. Only the modifications in respect to the reference are mentioned. The minerals are defined in the reference.

\subsection{Micromanipulation}

Micromanipulation was performed for single cell separation of yeast cells in order to ensure the purity of the isolated hybrid strains. The micromanipulation system used is based on a development of Pierre de Fonbrune (US-Patent 1987733-1987734) and was manufactured by Etablissements Beaudoin (Paris, France).

\subsection{DNA Isolation and ITS 1-5.8S-ITS 2 Amplification}

In general, DNA was isolated from the pure cultured cells using InstaGene ${ }^{\mathrm{TM}}$ Matrix kit (Bio-Rad, Munich, Germany), according to the manufacturer's protocol.

High-quality DNA extracts were required for some applications. Therefore, DNA used for specific amplified polymorphic DNA (SAPD)-PCR was purified using the DNeasy Blood \& Tissue Kit (Qiagen, Hilden, Germany), according to the manufacturer's protocol for purification of total DNA from yeasts.

The internal transcribed spacer (ITS 1-5.8S-ITS 2) region was sequenced for species identification of the isolated yeasts. Amplification of the ITS region was performed in a mastercycler gradient thermocycler (Eppendorf, Hamburg, Germany) with oligonucleotide primers ITS 4 (5'-TCCTCCGCTTATTGATATGC-3') and ITS 5 (5'-GGAAGTAAAAGTCGTAACAAGG-3'; White et al., 1990). The following PCR conditions were used: pre-denaturation for $5 \mathrm{~min}$ at $95{ }^{\circ} \mathrm{C}$, then amplification for 35 cycles including $1 \mathrm{~min}$ at $94{ }^{\circ} \mathrm{C}$, followed by annealing for $1 \mathrm{~min}$ at $55^{\circ} \mathrm{C}$ and finally an extension for $1 \mathrm{~min}$ at $72{ }^{\circ} \mathrm{C}$, then finally a post-extension step for 10 $\min$ at $72^{\circ} \mathrm{C}$.

For the identification of isolated hybrids, a further restriction analysis of several gene regions (CAT8, CYR1, GSY1, MET6, and OPY1) occurring on different chromosomes was carried out according to González et al. (2006). Amplification of DNA was performed under the following conditions: 5 min at $95{ }^{\circ} \mathrm{C}$, then 40 cycles including $1 \mathrm{~min}$ at $94{ }^{\circ} \mathrm{C}, 2 \mathrm{~min}$ at $55.5^{\circ} \mathrm{C}$ and $2 \mathrm{~min}$ at $72{ }^{\circ} \mathrm{C}$, followed by a final extension step for $10 \mathrm{~min}$ at $72{ }^{\circ} \mathrm{C}$.

All primers were obtained from Sigma-Aldrich (Steinheim, Germany). All the other PCR components used were from peqlab (Erlangen, Germany).

\subsection{Restriction Enzyme Digestion}

After PCR, a restriction enzyme digestion of the amplified regions was performed in order to combine the resulting fragments into groups and at least one amplificate of each group was sequenced by LGC Genomics (Berlin, Germany) in order to identify the organism. Before sequencing, the amplificates were purified with a 
Purification Kit (Qiagen, Hilden/Germany). The resulting sequences were identified using the Basic Local Alignment Search Tool Nucleotide algorithm (BLASTN) of the National Centre for Biotechnology Information (NCBI). The fragment patterns of Saccharomyces hybrids were compared to those of Saccharomyces type species in order to identify the parental species of the hybrids by their restriction patterns.

The following FastDigest ${ }^{\circledR}$ restriction enzymes were used for the ITS amplification product of yeasts: HhaI (interface $5^{\prime}-\mathrm{GC}^{\wedge} \mathrm{GC}-3^{\prime}$ ), HaeIII (interface $5^{\prime}-\mathrm{GG}^{\wedge} \mathrm{CC}-3^{\prime}$ ) and Hinfl (interface $5^{\prime}-\mathrm{G}^{\wedge} \mathrm{ANTC}-3^{\prime}$; N stands for a random base) (Divol \& Lonvaud-Funel, 2005). From the PCR product, $8.7 \mu \mathrm{L}$ were digested with $0.3 \mu \mathrm{L}$ restriction endonuclease in a final volume of $10 \mu \mathrm{L}$ and incubated at $37{ }^{\circ} \mathrm{C}$ for $20 \mathrm{~min}$ and then at $65^{\circ} \mathrm{C}$ for $20 \mathrm{~min}$.

During the screening of microorganisms, some yeasts species were isolated which were supposed to be hybrids. Therefore, a further restriction enzyme digestion was used to proof this assumption and identify the parental species. For restriction enzyme digestion of the different gene regions of the hybrids, $15 \mu \mathrm{L}$ of the PCR product were digested with $0.3 \mu \mathrm{L}$ restriction endonuclease in a final volume of $20 \mu \mathrm{L}$ and incubated at $37^{\circ} \mathrm{C}$ for $16 \mathrm{~h}$ or $30 \mathrm{~min}$ in the case of "FastDigest" enzymes. MspI and HhaI (an isoschizomer of CfoI) were used for the restriction of the amplification product of gene CAT8. CYRI was digested with HaeIII and MspI, GSY1 with MspI, and MET6 with HaeIII, Hinfl and ScrFI. Scrfl and HaeIII were used for OPYI (González et al., 2006).

All components for the restriction digest were purchased from Fisher Scientific (Schwerte, Germany). Resulting fragments were resolved on $3 \%(\mathrm{w} / \mathrm{v})$ agarose gels. After staining the gels for $30 \mathrm{~min}$ in an ethidium bromide staining solution, RFLP patterns were documented under UV light (BioVision CN 3000, Vilber-Lourmat, Eberhardzell, Germany). The size of the fragments was determined using Bio-1D software (Vilber Lourmat, Eberhardzell, Germany) by comparison with the molecular size marker GeneRuler DNA Ladder Mix SM0331 (Fisher Scientific, Schwerte, Germany).

\subsection{SAPD-PCR}

The DNA fingerprinting method SAPD-PCR was carried out according to Blättel et al. (2013) for the further identification of the Saccharomyces species.

\subsection{Determination of Sugars, Ethanol and Amino Acids}

The glucose and fructose concentration in synthetic media were determined using an enzymatic assay (D-Glucose/D-Fructose-Kit, R-Biopharm, Darmstadt, Germany). Ethanol and sugars in must and wine samples were analyzed with high-performance liquid chromatography (HPLC; autoinjector SIL-10AD, pump LC-10AD, integrator C-R8A, Shimadzu, Kyoto, Japan) on an Aminex ${ }^{\circledR} \mathrm{HPX}-87 \mathrm{H}$ ion exclusion column $(300 \mathrm{~mm} \times 7.8 \mathrm{~mm}$, Biorad, Munich, Germany), according to Pfeiffer and Radler (1985), using an external standard (glucose $10.0 \mathrm{~g}$, fructose $10.0 \mathrm{~g}$, ethanol $39.0 \mathrm{~g}$, adjusted to $1 \mathrm{~L}$ with deionized water). Amino acids in must samples were also determined with HPLC (autoinjector SIL - 10Ai, pump LC - 10Ai, UV-detector RF - 535, Shimadzu, Kyoto, Japan) on a ProntoSIL Spheribond ODS 2 column (250 $\mathrm{mm} \times 4 \mathrm{~mm}$, Bischoff, Leonberg, Germany). Derivatization was carried out with FMOC-Cl. Each sample was analyzed three times.

\subsection{Determination of the Weight of Freeze-Dried Cells}

Yeasts were cultured at $30{ }^{\circ} \mathrm{C}$ and harvested by centrifugation $(8000 \mathrm{~g}, 10 \mathrm{~min})$ during the exponential growth phase after 72 hours. The cells were washed twice with $0.9 \%(\mathrm{w} / \mathrm{v}) \mathrm{NaCl}$ and pelleted by centrifuging. Cell pellets were freeze-dried for 72 hours in a Lyovac GT2 (Steris, Braunsfeld, Germany). In order to correlate optical density with the weight of freeze-dried cells a calibration curve was generated. For this reason lyophilized cells $\left(30-250 \mu \mathrm{g} / \mathrm{mL}\right.$ ) were suspended in $0.9 \%$ (w/v) $\mathrm{NaCl}$ and then $\mathrm{OD}_{600}$ was measured. These determinations were performed three times for each yeast strain.

\subsection{Sugar Uptake Determination}

Quadruplicate assays for sugar uptake by the cells were performed to two cultures of the same yeast strain, according to the method described by Walsh et al. (1994), with some modifications. D-[U- $\left.{ }^{14} \mathrm{C}\right]$ glucose $[255$ $\mathrm{mCi} / \mathrm{mmol}(9.44 \mathrm{GBq} / \mathrm{mmol})]$ was obtained from Hartmann Analytic (Braunschweig, Germany) and D-[U- $\left.{ }^{14} \mathrm{C}\right]$ fructose $[300 \mathrm{mCi} / \mathrm{mmol}(11.11 \mathrm{GBq} / \mathrm{mmol})]$ from American Radiolabeled Chemicals, Inc (St. Louis, U.S.A.).

Yeasts were grown stationary in modified B-medium (Heerde \& Radler, 1978) with $100 \mathrm{~g} / \mathrm{L}$ glucose and $100 \mathrm{~g} / \mathrm{L}$ fructose at $15^{\circ} \mathrm{C}$. Cultures in exponential phase were harvested by centrifugation $(8000 \mathrm{x} \mathrm{g}, 5 \mathrm{~min})$. Cells were washed three times and resuspended in $100 \mathrm{mM}$ potassium/sodium phosphate buffer ( $\mathrm{pH} 5.9$ ) to obtain an $\mathrm{OD}_{600}$ of $2.0-3.5$. Yeast cells $(50 \mu \mathrm{L})$ and $10 \mathrm{mM}$ radiolabeled glucose or fructose $(12.5 \mu \mathrm{L})$ were incubated separately at $28{ }^{\circ} \mathrm{C}$ for $3 \mathrm{~min}$, then mixed and incubated for 5 and $15 \mathrm{~s}$. Uptake was stopped by adding $62.5 \mu \mathrm{L}$ of the yeast/sugar mixture solution to $3.0 \mathrm{~mL}$ of ice-cold100 mM potassium/sodium phosphate buffer (pH 5.9). Cells 
were collected quickly with the aid of a vacuum device (FH 225V Ten-Place Filter Manifold, Hoefer Pharmacia Biotech, San Francisco, USA) and washed on glass microfiber filters (Whatman GF/C, Sigma, Taufkirchen, Germany) with $3.0 \mathrm{~mL}$ of $100 \mathrm{mM}$ potassium/sodium phosphate buffer ( $\mathrm{pH}$ 5.9). Filters were then transferred into scintillation vials containing $4.0 \mathrm{~mL}$ of scintillant (Roth, Karlsruhe, Germany). Radioactivity was measured with a Winspectral liquid scintillation counter (PerkinElmer Wallac, Absteinach, Germany).

The control blank in each experiment consisted of radiolabeled glucose or fructose and yeast cells added to ice-cold buffer. The non-specific binding of sugar to yeast cells and filters was determined using the following equation:

$$
\left[{ }^{14} \mathrm{C}\right]-\text { sugar uptake }\left[\frac{\mathrm{nmol}}{\mathrm{mg}} \text { freeze dry weight }\right]=\frac{(\text { activity of sample }- \text { activity of control blank })[\text { dpm }] \times 10000}{\text { specific activity }\left[\frac{d p m}{n m o l}\right] \times \text { weight }[\mathrm{mg} \text { freeze dry weight }]}
$$

\subsection{Determination of Enzyme Activities}

The yeast cells were cultivated at $20^{\circ} \mathrm{C}$ in modified B-medium (Heerde \& Radler, 1978) with $50.0 \mathrm{~g} / \mathrm{L}$ of each glucose and fructose for hexokinase determinations. The yeasts were grown at $20{ }^{\circ} \mathrm{C}$ and $30{ }^{\circ} \mathrm{C}$ in order to evaluate for alcohol dehydrogenase activities. Cell extracts were obtained according to the protocols of Mateo and Di Stefano (1997) and Lomolino et al. (2001) with some modifications. Two milliliters of a yeast culture $\left(\mathrm{OD}_{600} 1.0\right)$ were centrifuged at $3000 \mathrm{x}$ g for $5 \mathrm{~min}$. The cell pellets were washed twice with deionized water and incubated for $15 \mathrm{~min}$ at $25{ }^{\circ} \mathrm{C}$ in buffer A (sorbitol $182.2 \mathrm{~g} / \mathrm{L}$; dithiothreitol $4.6 \mathrm{~g} / \mathrm{L}$ in $10 \mathrm{mM}$ citrate-phosphate buffer, $\mathrm{pH}$ 5.5). Afterwards, the suspensions were centrifuged at $1000 \mathrm{xg}$ for $5 \mathrm{~min}$ and the cells resuspended in $2 \mathrm{~mL}$ of buffer B (sorbitol $182.2 \mathrm{~g} / \mathrm{L}$; dithiothreitol $0.16 \mathrm{~g} / \mathrm{L}$, Na-EDTA $37.2 \mathrm{~g} / \mathrm{L}$ in $10 \mathrm{mM}$ citrate buffer, $\mathrm{pH}$ 5.5). Twenty microliters of this suspension were mixed with $180 \mu \mathrm{L}$ lyticase from Arthrobacter luteus $(200 \mathrm{U} / \mathrm{mL}$, Sigma-Aldrich, Steinheim, Germany) and incubated on a shaker $(950 \mathrm{rpm})$ for $2.5 \mathrm{~h}$ at $37{ }^{\circ} \mathrm{C}$. The resulting spheroblasts were centrifuged again $(1000 \mathrm{x} \mathrm{g}, 5 \mathrm{~min})$ and suspended in $50 \mathrm{mM}$ HEPES buffer $(\mathrm{pH} 7.5)$. The suspensions were shaken for $5 \mathrm{~min}$ at $1100 \mathrm{rpm}$ and subsequently incubated in an ultrasonic bath for $10 \mathrm{~min}$. Cell-free extracts used for enzyme determinations were obtained after centrifugation at $10000 \mathrm{x} g$ for $5 \mathrm{~min}$.

The protein concentration in the yeast cell-free-extracts were determined by the Bradford method using Roti $\AA$-Quant (Roth, Karlsruhe, Germany).

Hexokinase activity was measured with both glucose and fructose as substrates, according to the method of Berthels et al. (2008). The enzymatic assay was monitored at $340 \mathrm{~nm}$ and specific activities were expressed as units/mg protein. $\mathrm{K}_{\mathrm{m}}$ and $\mathrm{V}_{\max }$ values for hexokinase activity were determined using sugar concentrations at 0.5 , $1.0,2.0,3.0,5.0$, and $10 \mathrm{mM}$.

Alcohol dehydrogenase activity was measured with a method described by Dickinson and Dack (2001) with 50 $\mu \mathrm{L}$ of a cell extract and $950 \mu \mathrm{L}$ of substrate solution $(100 \mu \mathrm{L} 12 \mathrm{mg} / \mathrm{mL}$ NAD; $100 \mu \mathrm{L} 100 \%$ ethanol; $750 \mu \mathrm{L} 50$ $\mathrm{mM}$ Tris/ $\mathrm{HCl}$ buffer, $\mathrm{pH}$ 7.2). The enzymatic assay was monitored at $340 \mathrm{~nm}$ and specific activities were expressed as units/mg protein.

\section{Results}

\subsection{Succession of Saccharomyces Yeasts and Concentration of Sugars during Fermentation}

A steel cask (cask 1) was selected and was studied from the beginning until the end of fermentation without any stuck in the first year of sampling, 2011. At the beginning, several wild yeasts of the genera Hanseniaspora, Candida, Pichia, and Metschnikowia were isolated (data not shown). However, we focus in this paper on the main wine yeasts from the genus Saccharomyces, which dominated fermentation at higher ethanol levels of 7 vol $\%(\mathrm{v} / \mathrm{v})$ and above. From this genus, only $S$. bayanus was isolated from cask 1 investigated throughout the fermentation without stuck. We started the sampling of cask 2 on day 26 of the fermentation, because of the development of stuck at that time. During the stuck period, which lasted 28 days, only S. bayanus could be isolated, similar to cask 1 without the stuck fermentation. SAPD-PCR was performed to verify the identity of the Saccharomyces species isolated (Table 3). 
Table 3. SAPD-PCR fragment patterns from Saccharomyces species

\begin{tabular}{lll}
\hline Species & Strain & Amplification products using the primer A-Not in bp rounded to 10 \\
\hline S. bayanus & DSM 70412 & $2,6302,3001,9601,7301,5701,4001,1001,020890730610550310$ \\
S. bayanus & HL 77 & $2,6302,3001,9601,7301,5701,4001,1001,020890730610550310$ \\
\hline
\end{tabular}

Note. ${ }^{\mathrm{T}}$ : type strain.

Yeasts of the genus Saccharomyces can only be separated into two groups with the restriction analysis of the ITS region using the FastDigest ${ }^{\circledR}$ restriction enzyme HaeIII (Blättel, 2012). Group I, including S. cerevisiae, shows a different fragment pattern compared to group II, including S. bayanus and S. kudriavzevii (Table 4). Restriction digestion with enzymes $H h a \mathrm{I}$ and Hinf $\mathrm{I}$ results in similar patterns for all yeasts of the Saccharomyces sensu stricto group (data not shown).

Table 4. Restriction fragment patterns of the ITS region with enzyme HaeIII from different Saccharomyces species

\begin{tabular}{lll}
\hline Restriction pattern & Fragments using HaeIII in bp rounded to 10 & Saccharomyces species \\
\hline I & 860740650500240170 & S. cerevisiae, S. paradoxus \\
II & 580320240170 & S. bayanus, S. kudriavzevii \\
I/II & 860740650500320240170 & S. cerevisiae $\times$ S. kudriavzevii $\times$ S. bayanus \\
\hline
\end{tabular}

The fermentation was continuing in cask 2 and on day 54, another yeast species besides $S$. bayanus was isolated from that sampling with a remarkable restriction pattern of the internal transcribed spacer (ITS 1-5.8S-ITS 2) regions using enzyme HaeIII. This pattern was a combination of group I and group II of the Saccharomyces species restriction patterns (Table 4). To prove whether the isolate was a triple hybride or possibly a mixture of three yeast species a single cell separation was performed by micromanipulation under optical control in order to ensure purity of these cultures and to exclude a mixed culture of several species. After a single cell manipulation and growing a culture starting from a single cell, a further restriction analysis of different gene regions from the grown cells, according to González et al. (2006), showed that the isolate HL78 were most likely triple hybrids of the mother species S. cerevisiae, S. kudriavzevii and S. bayanus (Table 5). From day 54 on, this hybrid was the dominant yeast strain in cask 2 until the end of the fermentation.

Table 5. RFLP analysis of different gene regions of the DNA from yeasts of the genus Saccharomyces and hybrids isolated from three different times of sampling after stuck fermentation

\begin{tabular}{|c|c|c|c|c|c|c|c|c|c|c|}
\hline \multirow{2}{*}{ Species/Strain } & \multirow{2}{*}{$\begin{array}{l}\text { GSYI } \\
\text { MspI }\end{array}$} & \multicolumn{2}{|c|}{ OPY1 } & \multicolumn{2}{|c|}{ CYR1 } & \multicolumn{2}{|c|}{ CAT8 } & \multicolumn{3}{|c|}{ MET6 } \\
\hline & & ScrFI & HaeIII & MspI & HaeIII & HhaI & MspI & HinfI & HaeIII & ScrFI \\
\hline S. kudriavzevii & 350300200 & 750 & 510250 & (570) $460(150)$ & 290200170100 & 590200 & 490240 & 620 & 680 & 680 \\
\hline CBS $8840^{\mathrm{T}}$ & A & A & A & A & A & A & A & A & A & A \\
\hline S. bayanus & 400350 & 560310260220 & 760400350 & 570 & 570 & 750 & 320280240 & 620 & 480200 & 680610 \\
\hline DSM $70412^{\mathrm{T}}$ & B & B & B & B & B & B & B & A & B & B \\
\hline S. cerevisiae & 600200 & 460310 & 760 & 400200 & 570 & 750 & 690 & 450200 & 680 & 680 \\
\hline DSM $70449^{\mathrm{T}}$ & $\mathrm{C}$ & $\mathrm{C}$ & $\mathrm{C}$ & $\mathrm{C}$ & B & B & $\mathrm{C}$ & B & A & A \\
\hline S. paradoxus & 450350 & 460310 & 510250 & 400200 & 390220 & 750 & 750 & 620 & 680 & 680 \\
\hline CBS $432^{\mathrm{T}}$ & $\mathrm{D}$ & $\mathrm{C}$ & A & $\mathrm{C}$ & $\mathrm{D}$ & B & $\mathrm{D}$ & A & A & A \\
\hline Isolate & 600350300 & 750460310 & 760400250 & 570460400150 & 570290200170 & 750590200 & 690490240 & 620 & 680 & 680 \\
\hline Strain HL 78 & $\mathrm{AC}$ & $\mathrm{AC}$ & $\mathrm{ABC}$ & $\mathrm{ABC}$ & $\mathrm{AB}$ & $\mathrm{AB}$ & $\mathrm{AC}$ & A & $\mathrm{A}$ & A \\
\hline Isolate & 600350300 & 750460310 & 760400250 & 570460400150 & 570290200170 & 750590200 & 690490240 & 620 & 680 & 680 \\
\hline Strain 82.14 & $\mathrm{AC}$ & $\mathrm{AC}$ & $\mathrm{ABC}$ & $\mathrm{ABC}$ & $\mathrm{AB}$ & $\mathrm{AB}$ & $\mathrm{AC}$ & A & A & A \\
\hline Isolate & 600350300 & 750460310 & 760510250 & 570460400150 & 570290200170 & 750590200 & 690490240 & 620 & 680 & 680 \\
\hline Strain 96.1 & $\mathrm{AC}$ & $\mathrm{AC}$ & $\mathrm{AC}$ & $\mathrm{ABC}$ & $\mathrm{AB}$ & $\mathrm{AB}$ & $\mathrm{AC}$ & A & A & A \\
\hline
\end{tabular}

Note. GSY1, OPY1, CYR1, CAT8, MET6: nuclear genes, located in different chromosomes. 
A stuck fermentation was again observed in the sampled cask 6 in the second year 2012 of sampling. On day 40 during fermentation in cask $6, S$. bayanus was the main yeast strain and the only yeast of the genus Saccharomyces that could be isolated from the young wine. The cell titer decreased during six weeks of stuck from $10^{5}$ to $10^{3}$ colony forming units (CFU) per ml. After six weeks of stuck, $5 \mathrm{~L}$ of the young wine were withdrawn from cask 6 and were inoculated with the triple hybrid $S$. cerevisiae $\times S$. kudriavzevii $\times S$. bayanus strain HL 78. The incubation of the $5 \mathrm{~L}$ sample was performed at $15{ }^{\circ} \mathrm{C}$ and fermentation continued immediately after inoculation. In parallel, a second sample $(5 \mathrm{~L})$ of the young wine withdrawn from cask 6 were incubated in the same conditions as control without the addition of the triple hybrid strain. Also in this case fermentation continued, but started two weeks later. At that time, the triple hybrid was also isolated from both this control as well as from the inoculated $5 \mathrm{~L}$ carboy (Figure 1).

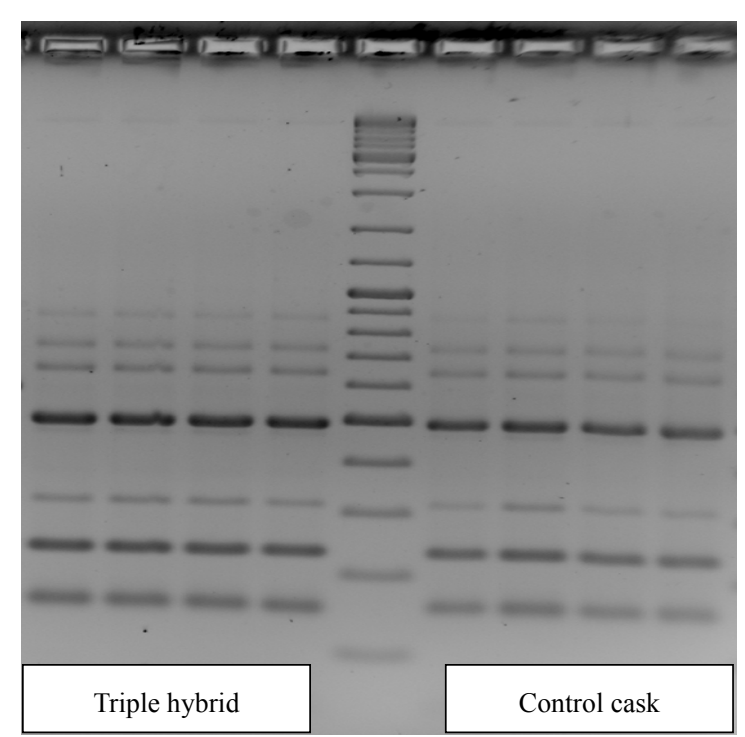

Figure 1. Restriction enzyme digestion patterns of the ITS region from yeasts digested with restriction enzyme HaeIII; Isolated yeast strains from must inoculated with the triple hybrid $S$. cerevisiae $\times S$. kudriavzevii $\times S$. bayanus and from a control cask after spontaneous restart of fermentation after stuck

In addition to the microbial analysis, the concentration of glucose and fructose was determined in the casks investigated. During both years of sampling, 2011 and 2012, low glucose:fructose ratios were found in all casks that showed stuck or sluggish fermentation (Figure 2). The casks sampled in 2011 showed glucose:fructose ratios from 0.04 (cask 3) to 0.11 (cask 4) on day 26 of the fermentation. The cask with stuck fermentation in 2012 showed a glucose:fructose ratio of 0.42 (cask 6) on day 40 of the fermentation.

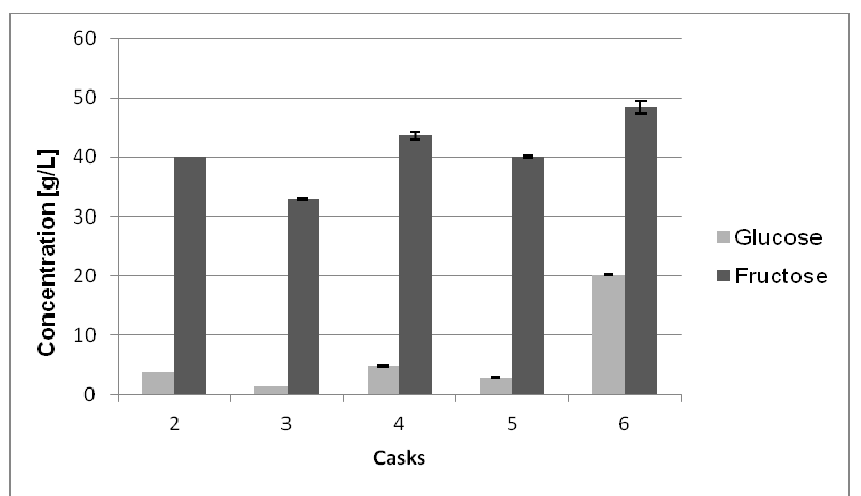

Figure 2. Glucose:fructose ratios of selected casks at stuck or sluggish stages of fermentation during two years of sampling in 2011 and 2012 in a German winery

(casks 2, 3, 4, and 5: vintage from 2011; cask 6: vintage from 2012) 


\subsection{Growth Experiments and Sugar Consumption of the Yeasts Isolated}

In order to verify the observations from the vineyard under controlled laboratory conditions, the two dominant wine yeast strains of the genus Saccharomyces, S. bayanus strain HL 77 and the triple hybrid S. kudriavzevii $\times$ S. cerevisiae $\times$ S. bayanus strain HL 78 (cf. Tables 4 and 5) were cultivated at a similar temperature to that in the wine cellar of $15{ }^{\circ} \mathrm{C}$ in a synthetic medium (B-medium) with a composition close to grape must. The hybrid showed a delayed growth of 3 days to reach an OD of 0.5 and a flatter growth curve compared to S. bayanus at the beginning of the fermentation (Figure 3). Since the ability of yeasts to uptake and consume sugars plays an important role as a cause of stuck fermentations, the yeasts were also tested for sugar consumption. The hybrid showed a significantly better consumption of fructose compared to $S$. bayanus (Figure 3 ) and utilization of fructose increased in the second half of the fermentation. A residual sugar concentration of $1 \mathrm{~g} / \mathrm{L}$ glucose and $1 \mathrm{~g} / \mathrm{L}$ fructose was left after 25 days of fermentation. In the medium inoculated with $S$. bayanus, $8.0 \mathrm{~g} / \mathrm{L}$ fructose and $1.5 \mathrm{~g} / \mathrm{L}$ glucose were left at this time, although this yeast strain showed faster growth in the synthetic B-medium (Figure $3)$.
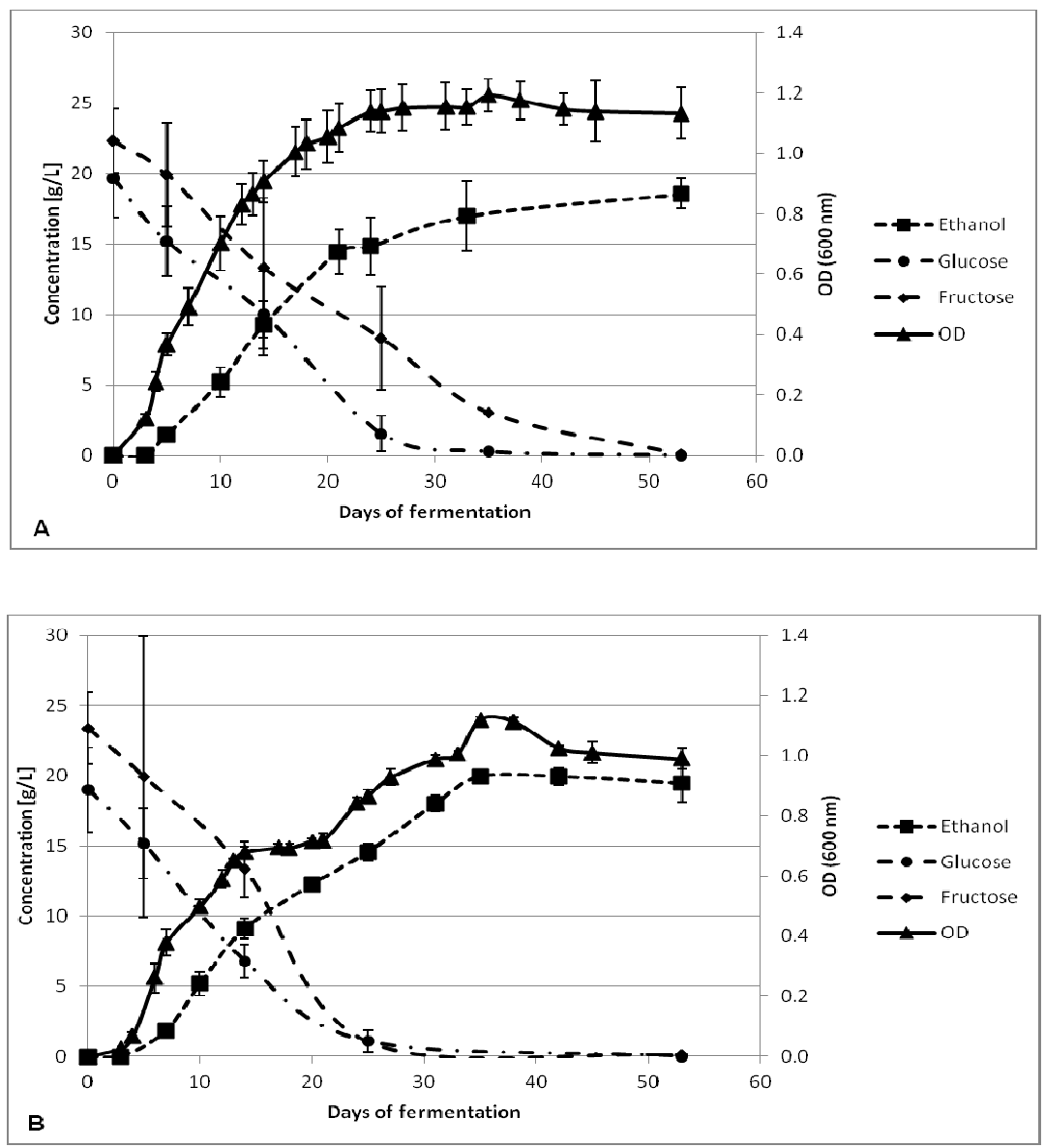

Figure 3. Growth, sugar consumption and ethanol production of S. bayanus strain HL 77 (A) and the hybrid $S$. cerevisiae $\times$ S. kudriavzevii $\times S$. bayanus strain HL $78(\mathrm{~B})$ in synthetic B-medium at $15^{\circ} \mathrm{C}$

Fermentation by both yeast strains was tested in relation to the ammonium sulfate concentration of the synthetic B-medium, as nutrient deficiencies, especially the availability of an ammonium or organic nitrogen source, can cause stuck fermentation (Jiranek et al., 1995). Therefore, the yeasts were grown at $15^{\circ} \mathrm{C}$ in synthetic B-medium with $25 \%, 50 \%$ and $100 \%$ of the amino acid concentration as used in the original B-medium (2.2 Sampling and Cultivation). To test the influence of YAN, $\left(\mathrm{NH}_{4}\right)_{2} \mathrm{SO}_{4}$ was added to the synthetic B-medium in concentrations from 0.0 to $2.5 \mathrm{~g} / \mathrm{L}$.

With reduced concentrations of amino acids in the synthetic B-medium, the S. bayanus strain HL 77 showed significantly slower usage of both sugars, glucose and fructose (Figure 4). A residual fructose concentration of $4.6 \mathrm{~g} / \mathrm{L}$ was found in the cultures with an amino acid concentration of $25 \%$ compared to the original medium. 


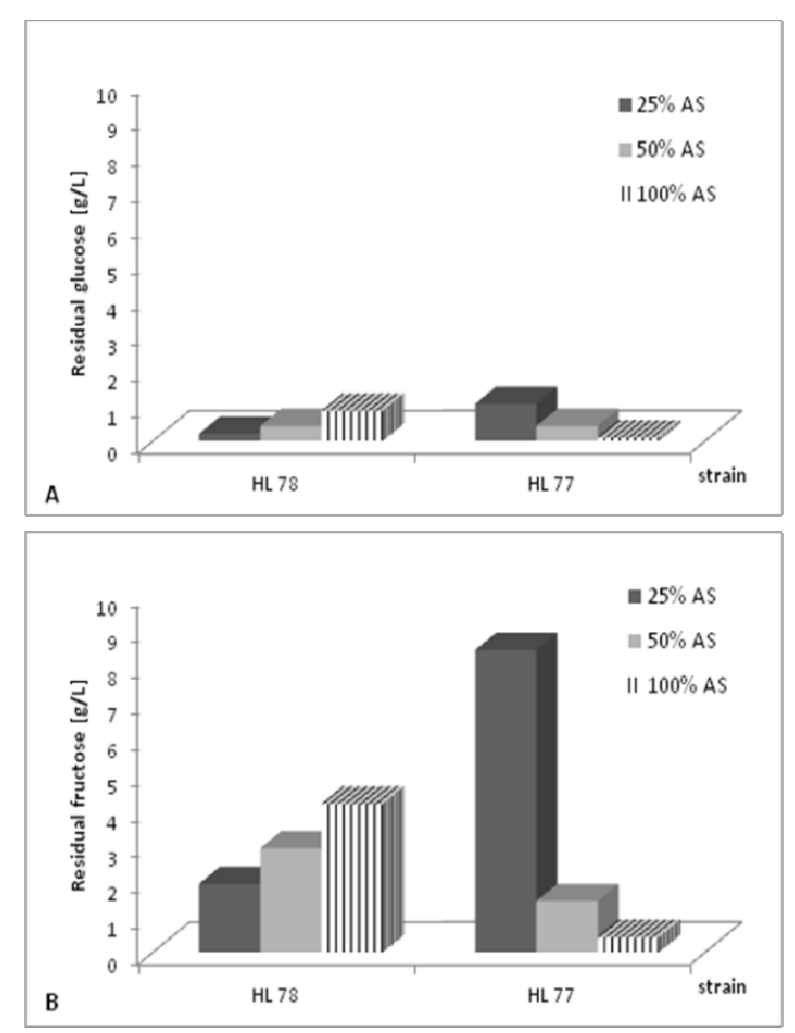

Figure 4. Residual glucose (A) and fructose (B) concentration in a culture of the S. cerevisiae $\times$ S. kudriavzevii $\times$ S. bayanus strain HL 78 and the S. bayanus strain HL 77 in relation to the amino acid concentration of synthetic B-medium after 32 days of fermentation

Uptake or utilisation of glucose was dependent on the amino acid concentration, but less than $1.0 \mathrm{~g} / \mathrm{L}$ was left after fermentation in the medium with $25 \%$ of amino acids.

The yeast isolates $S$. bayanus HL77 and the triple hybrid $S$. cerevisiae $\times$ S. kudriavzevii $\times$ S. bayanus strain HL78 were incubated in synthetic B-medium with varying concentrations of amino acids. The results of this experiment (Figure 4) showed that the sugar consumption of the triple hybrid strain HL 78 was less dependent on the amino acid concentration of the medium. With reduced amino acid levels of $50 \%$ and $25 \%$, the degradation of both glucose and fructose was even slightly better than with addition of $100 \%$ amino acids in the medium. HPLC analysis of samples from cask 1 and cask 2 from vintage 2011/2012 showed that only a total of $1.11 \mathrm{~g} / \mathrm{L}$ of amino acids were found in the sample during stuck fermentation (after 26 days of fermentation) compared to $1.37 \mathrm{~g} / \mathrm{L}$ in the sample (after 29 days of fermentation) from normal fermentation (Table 6). Especially, there was a complete depletion of glutamine and asparagine in the cask with stuck fermentation. 
Table 6. Concentrations of amino acids [mg/L] in samples from normal (Cask 1, after 29 days of fermentation) and stuck (Cask 2, after 26 days of fermentation) fermentation (n.d.: not detected)

\begin{tabular}{lll}
\hline Amino acid & Cask 1 & Cask 2 \\
\hline L - aspartic acid & n.d. & 3.39 \\
L - glutamic acid & 11.47 & 8.20 \\
L - asparagine & 13.54 & n.d. \\
L - glutamine & 60.69 & n.d. \\
L - serine & 1.94 & 5.60 \\
L - glycine & 23.18 & 19.40 \\
L - alanine & 4.58 & 14.12 \\
L - proline & 817.89 & 988.03 \\
L - methionine & 427.36 & 70.56 \\
L - isoleucine & 14.30 & n.d. \\
L - arginine & n.d. & 3.23 \\
\hline Total & 1374.95 & 1112.52 \\
\hline
\end{tabular}

Both isolated yeast strains $S$. bayanus and $S$. cerevisiae $\times S$. kudriavzevii $\times S$. bayanus were able to utilize glucose as well as fructose with no added $\left(\mathrm{NH}_{4}\right)_{2} \mathrm{SO}_{4}$, but only with amino acids as a nitrogen source in the synthetic B-medium (Figure 5). The hybrid showed delayed sugar consumption compared to S. bayanus, with a reduced concentration of ammonium sulfate of the medium.
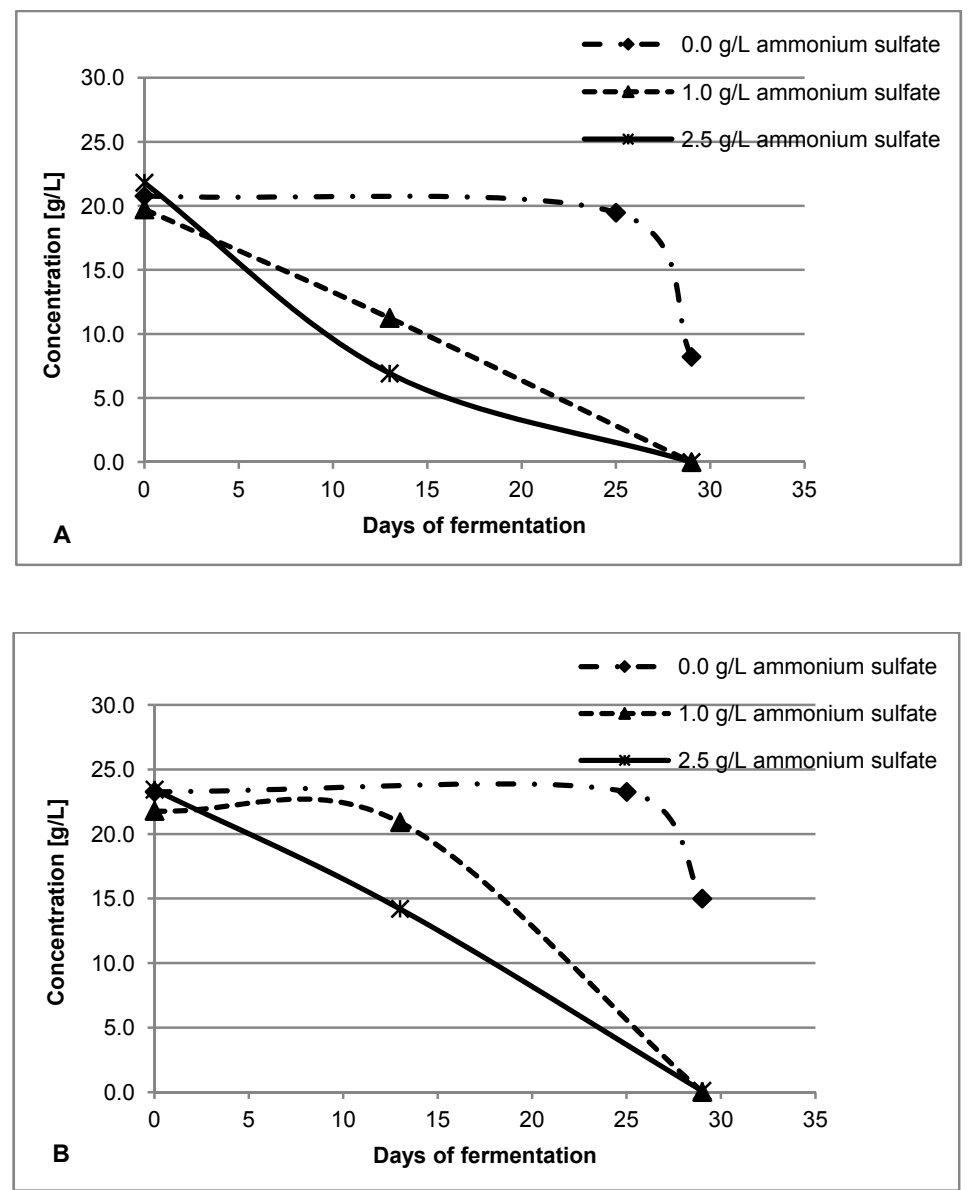

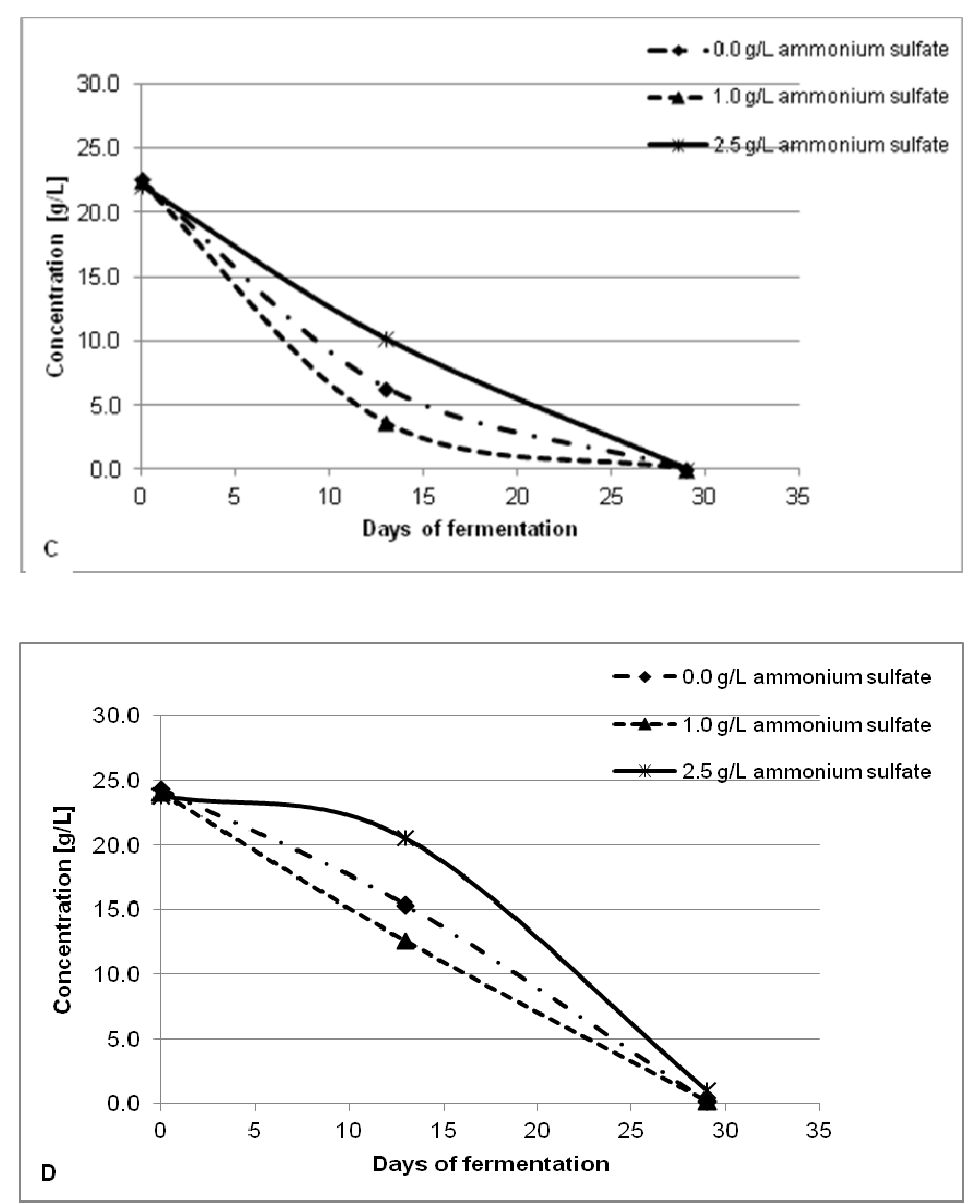

Figure 5. Sugar consumption of the triple hybrid S. cerevisiae $\times$ S. kudriavzevii $\times$ S. bayanus strain HL 78 (A: glucose, B: fructose) and the S. bayanus strain HL 77 (C: glucose, D: fructose) in relation to the ammonium sulfate concentration in synthetic medium

The S. cerevisiae starter culture strain Fermivin ${ }^{\circledR}$ tested, which was used as a control, was not able to grow and consume sugars without the addition of $\left(\mathrm{NH}_{4}\right)_{2} \mathrm{SO}_{4}$ to the medium (Figure 6).

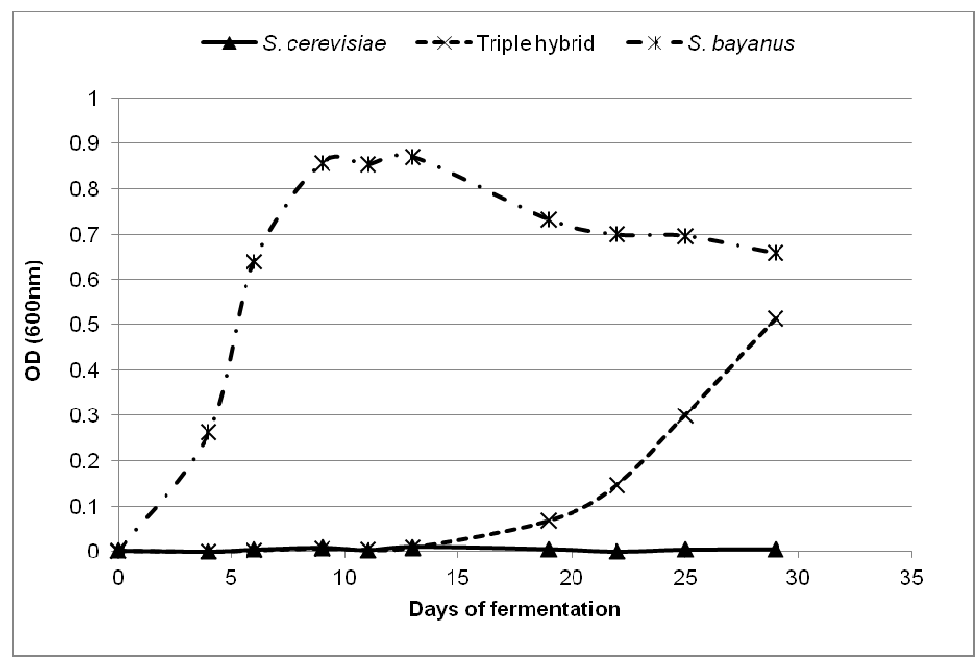

Figure 6. Growth of S. bayanus strain HL 77, the triple hybrid strain $S$. cerevisiae $\times$ S. kudriavzevii $\times$ S. bayanus strain $\mathrm{HL} 78$ and S. cerevisiae strain Fermivin ${ }^{\circledR}$ in synthetic medium without addition of $(\mathrm{NH})_{2} \mathrm{SO}_{4}$ as a nitrogen source 


\subsection{Sugar Uptake Rates of the Saccharomyces Strains}

The uptake rate of ${ }^{14} \mathrm{C}$-labeled sugars by cells of $S$. bayanus strain HL 77 and $S$. cerevisiae $\times$ S. kudriavzevii $\times$ S. bayanus strain HL 78 was determined. Radioactivity was measured 5 and $15 \mathrm{~s}$ after addition of the sugars. As shown in Figure 7A, glucose uptake by $S$. bayanus after $5 \mathrm{~s}$ is about twofold higher than that of fructose. Nevertheless, the uptake of both sugars was equal after $15 \mathrm{~s}$. By contrast, fructose transport by $S$. cerevisiae $\times S$. kudriavzevii $\times S$. bayanus strain HL 78 was about threefold higher than that of glucose, both after 5 and $15 \mathrm{~s}$ (Figure 7B). This behavior is in line with the somewhat fructophilic nature of the hybrid strain.
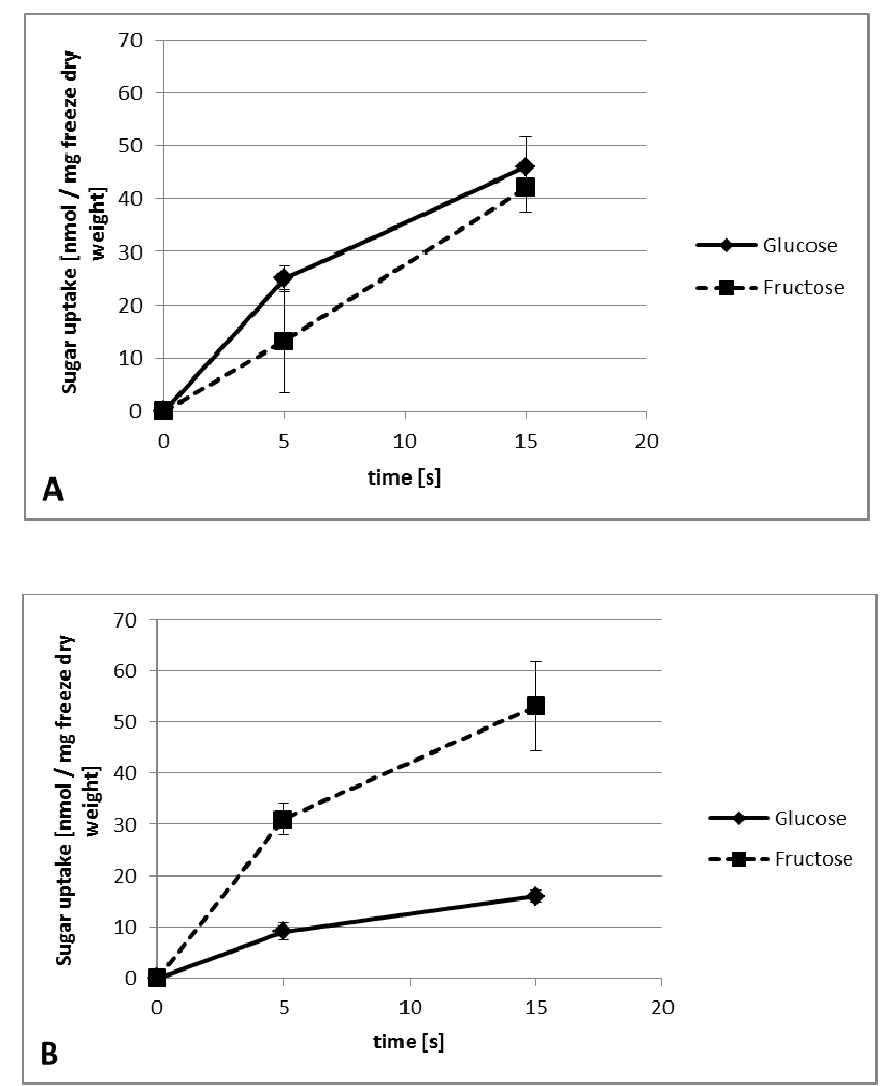

Figure 7. Sugar uptake of S. bayanus strain HL 77 (A) and S. cerevisiae $\times$ S. kudriavzevii $\times$ S. bayanus strain HL 78 (B) after 5 and $15 \mathrm{~s}$ in medium containing $2 \mathrm{mM}$ glucose or fructose

\subsection{Enzyme Activities Involved in Sugar Uptake}

The hexokinase activities measured in cell extracts of yeast isolates are summarized in Table 7. It should be kept in mind that these data are based on the activities of several hexokinase isoforms. The sugar conversion rate (Vmax) of glucose and fructose was generally higher in the hybrid strain HL 78 than in strain HL. It is noticeable that $\mathrm{V}_{\max }$ of the hexokinase activity of $S$. bayanus strain HL 77 with glucose is somewhat higher than with fructose but vice versa for the hybrid. $\mathrm{K}_{\mathrm{m}}$ values with fructose were considerable higher than for glucose. In comparison to $S$. bayanus $\mathrm{HL} 77$, the hybrid strain $\mathrm{HL} 78$ had a relative lower $\mathrm{K}_{\mathrm{m}}$ for fructose (5.50 versus 3.69 $\mathrm{mM})$. Thus, a relative high hexokinase affinity for fructose and a higher conversion rate may contribute to the more fructophilic character of the hybrid strain HL 78 compared to S. bayanus strain HL 77. 
Table 7. Enzymatic parameters of the hexokinase activities of $S$. bayanus strain HL 77 and $S$. cerevisiae $\times S$. kudriavzevii $\times S$. bayanus strain HL 78

\begin{tabular}{|c|c|c|c|c|}
\hline \multirow{2}{*}{ Enzymatic parameter } & \multicolumn{2}{|c|}{ S. bayanus strain HL 77} & \multicolumn{2}{|c|}{ S. cerevisiae $x$ S. kudriavzevii $x$ S. bayanus strain HL 78} \\
\hline & Glucose & Fructose & Glucose & Fructose \\
\hline $\mathbf{K}_{\mathrm{m}}[\mathbf{m} \mathbf{M}]$ & 1.01 & 5.50 & 0.83 & 3.69 \\
\hline $\mathbf{V}_{\max }[\mathbf{U} / \mathbf{m g}]$ & 0.93 & 0.88 & 1.24 & 1.38 \\
\hline$K_{m}$ for glucose: $K_{m}$ for fructose-ratio & 0.18 & & 0.22 & \\
\hline$V_{\max }$ for glucose: $V_{\max }$ for fructose-ratio & 1.06 & & 0.90 & \\
\hline
\end{tabular}

Alcohol dehydrogenase activities of the two yeast isolates are compared in Table 8 . The alcohol dehydrogenase of hybrid strain HL 78 works more effectively than that of S. bayanus strain HL 77 at both growth temperatures of $20{ }^{\circ} \mathrm{C}$ and $30{ }^{\circ} \mathrm{C}$. This result is another indication for the enhanced fermentation efficiency of the interspecific hybrid. With increasing growth temperature, the alcohol dehydrogenase of the hybrid strain increases, but that of S. bayanus strain HL 77 decreases. The latter observation may reflect the cold adaptation of this species.

Table 8. Alcohol dehydrogenase activities of strains S. bayanus HL 77 and S. cerevisiae $\times$ S. kudriavzevii $\times$ S. bayanus $\mathrm{HL} 78$ grown at $20^{\circ} \mathrm{C}$ and $30^{\circ} \mathrm{C}$

\begin{tabular}{lll}
\hline \multirow{2}{*}{ Strain } & \multicolumn{2}{l}{ Alcohol dehydrogenase activity [U/mg] } \\
\cline { 2 - 3 } & $20^{\circ} \mathrm{C}$ & $30{ }^{\circ} \mathrm{C}$ \\
\hline HL 77 & 0.41 & 0.22 \\
HL 78 & 2.17 & 4.39 \\
\hline
\end{tabular}

\section{Discussion}

The yeast strain most frequently found in the winery investigated during fermentation was Saccharomyces bayanus during both years of sampling, in 2011 and 2012, although $S$. cerevisiae is known as the main wine yeast in general and S. bayanus is found rarely (Dittrich \& Großmann, 2005). Ultee et al. (2013) have found a yeast strain which was identified as $S$. uvarum by that time, instead of $S$. cerevisiae in this winery. But today we assume, that this yeast strain has most likely also been $S$. bayanus. This might be due to the low fermentation temperature, between 12 and $15{ }^{\circ} \mathrm{C}$, in the cellar of the investigated winery. S. bayanus is known to be more psychrotrophic than S. cerevisiae (Serra et al., 2005; Belloch et al., 2008; Salvadó et al., 2011). The dominant yeast strain in both casks with stuck fermentation sampled during the stuck was also $S$. bayanus. However, it was replaced by a triple hybrid $S$. cerevisiae $\times$ S. kudriavzevii $\times S$. bayanus, which grew up during the stuck and continued and completed the fermentation. Several authors have isolated different hybrids in must or wine samples in Europe (Bradbury et al., 2006; González et al., 2008; Lopes et al., 2010). The hybrids have already been described as being involved in the winemaking process (González et al., 2006; Arroyo-López et al., 2009). Peris et al. (2012) postulated that hybrids between S. cerevisiae and S. kudriavzevii had already originated during the winemaking of the Romans and spread during the Late Middle Ages with the expansion of improved viticulture and enology practices. However, their role in overcoming stuck fermentation has not yet been recognized.

The hybrid should have been in the must from the beginning of the fermentation with a low cell titer and showed delayed growth compared to S. bayanus, which could also be proved in growth experiments in synthetic must. However, despite the delayed occurrence of the triple hybrid during fermentation in the winery because of slower growth at the beginning, the hybrid was able to restart and finish fermentation when nutrients, such as ammonia nitrogen and sugars, had already been reduced. Hybrids are supposed to be advantageous for winemaking because they are adapted to different fermenting conditions due to the combined characteristics of their parents, e.g. tolerance against high ethanol concentration and osmolarity of $S$. cerevisiae and tolerance against cool temperatures of S. kudriavzevii (González et al., 2006). Tronchoni et al. (2009) tested several Saccharomyces species and their hybrids for sugar consumption and the S. kudriavzevii type strain was the least affected by variations of temperature during fermentation. 
Our growth experiments showed that both yeast strains isolated, S. bayanus strain HL 77 and the triple hybrid strain HL 78, metabolize glucose and fructose, but the hybrid utilizes fructose significantly more efficient than $S$. bayanus, especially in the second stage of the fermentation (cf. Table 7; Figures 4, 5 and 7). We also detected a preference for fructose by the hybrid strain HL 78 on the level of sugar transport, whereas S. bayanus favored glucose. Enzymatic determinations suggest a higher fructose phosphorylation rate for the hybrid strain than for $S$. bayanus strain HL 77. Thus, the specific hexokinase activity supports the fructophilic character of the hybrid strain. In addition, the high alcohol dehydrogenase activity of the hybrid might contribute to a high fermentation rate. The mentioned abilities of the hybrid strain HL 78 are advantageous for a wine yeast strain and might be one of the main reasons why this strain is able to grow during stuck fermentation when glucose has already been reduced and residual fructose remains in excess. Tronchoni et al. (2009) observed that fructose fermentation was more inhibited by high ethanol levels than glucose fermentation. In general, natural musts contain nearly equal amounts of glucose and fructose (Fleet \& Heard, 1993), but many wine yeast strains prefer glucose over fructose, which may lead to undesirable residual amounts of fructose in wine and sluggish fermentation (Gafner \& Schütz, 1993; Berthels et al., 2004). Therefore, fructophilic yeast strains are advantageous for making dry wines. More fructose than glucose was left in all the casks with stuck fermentation sampled; the glucose:fructose ratios varied from 0.04 to 0.42 . Until these stages of fermentation, only S. bayanus was found in the casks.

The amount of nitrogen available is considered to be one of the main limiting factors for yeast growth in musts (Pretorius, 2000). The demand for YAN varies between $140 \mathrm{mg} / \mathrm{L}$ and $880 \mathrm{mg} / \mathrm{L}$ (Dittrich \& Großmann, 2005). It has been reported that concentrations of assimilable nitrogen below $140 \mathrm{mg} / \mathrm{L}$ impair fermentation by $S$. cerevisiae at normal sugar concentrations, and a concentration of ammonium ions below $25 \mathrm{mg} / \mathrm{L}$ is generally considered to be undesirable (Bely et al., 1990). This could also be the main reason why S. cerevisiae was not found as the main wine yeast in this winery as only $160 \mathrm{mg} / \mathrm{L}$ YAN was found in the wine, which decreased down to $40 \mathrm{mg} / \mathrm{L}$ after 15 days of fermentation.

Both yeast strains isolated, S. bayanus strain HL 77 and S. cerevisiae $\times$ S. kudriavzevii $\times$ S. bayanus strain HL 78, were able to grow in synthetic medium in the absence of an ammonium source when amino acids were present. For that reason, they are very good adapted to the low nitrogen conditions in the winery they were isolated from.

The hybrid strain HL 78 proved to be less dependent than S. bayanus strain HL 77 on the amino acid concentration of the culture medium for the sugar degradation. The S. cerevisiae starter culture tested showed no growth under these conditions. Jiranek et al. (1995) showed that amino acid utilization varies from one strain to another even between different wine yeasts of $S$. cerevisiae. Our experiments showed that the triple hybrid strain was less affected by amino acid deficiency which occurrs during stuck fermentations.

As it is quite time-consuming and expensive to determine the demand of amino acids and YAN of each potential starter culture, it would be profitable under some circumstances to use a yeast strain such as the triple hybrid, which is less dependent on the amino acid supply and ammonium content of the must. In combination with the better fructose utilization, it is a great advantage for a wine yeast strain to be able to grow in a stage of the fermentation when nutrients and sugars have already been reduced. On the other hand, as S. bayanus strain HL 77 seems to be much more dependent on the amino acid concentration for the utilization of glucose and especially fructose. Amino acid deficiencies in the must may lead to the stuck fermentations with high residual fructose concentrations observed (cf. Figure 4). In this case, the hybrid seems to take advantage and continue fermentation. Lower determined amino acid concentrations in cask 2 with stuck fermentation from vintage 2011/2012 compared to cask 1 with normal fermentation are another hint for this hypothesis. In this context, it is interesting to note that we found a complete depletion of L-glutamine in the barrels with stuck fermentations (cf. Table 6). This amino acid is a universal amino group donor in nitrogen metabolism.

\section{Conclusions}

This investigation can be seen as an exemplary model study to overcome stuck fermentation in special wineries which apply spontaneous fermentation. Generally, the wines produced by spontaneous fermentations exhibit a more complex and terroir typical sensory profile. This is the reason why some winemakers of the upper quality segment favour spontaneous fermentation despite the fact to observe stuck fermentation more likely than after applying normal starter cultures at the beginning the must fermentation. Some wine makers of the upper quality segment do not want to use commercial starter cultures. When an isolated winerey's own yeast strain as in this case a triple hybrid is used to continue fermentation after stuck the risk to change the characteristic desired aroma profiles of the winery would be minimized. It still has to be proved if similar Saccharomyces hybrids are responsible for overcoming stuck fermentations in other wineries which apply spontaneous fermentation.

As a prerequisite for the improvement of yeast strains and the generation of hybrids more reliable taxonomic 
markers are needed for the accurate determination of yeast strains involved in wine making. There are recent hints that at least one S. bayanus strain is a hybrid between S. eubayanus and S. uvarum. Genomic analysis revealed that $S$. uvarum is a sister species of $S$. eubayanus and $S$. bayanus should be a hybrid between these two species (Almeida et al., 2014; Boynton \& Greig, 2014). For a long time $S$. uvarum and $S$. bayanus were taken as varieties of $S$. bayanus (S. bayanus var. bayanus and $S$. bayanus var. uvarum). The genome sequence deposited as $S$. bayanus strain MCYC 623 (NCBI database) should be from an S. uvarum strain. Therefore, databases and culture collections need to be updated in order to be able to provide reliable data and strains for researchers, who want to use certain mother strains to produce hybrids.

The application of genetically engineered yeast strains is not allowed except two strains in the U.S. (S. cerevisiae strain ML01 and S. cerevisiae ECM001), which were generally recognized as safe (GRAS). However, the production and application of hybrids with improved and desired features is legal and possible. They can grow under certain limiting condition (e.g. ammonium deficiency) in the must under which the normal wine yeast $S$. cerevisiae is not able to grow. Based on the results of this study we recommend the generation and application of hybrid yeasts to improve wine making especially in the case of facing problems during spontaneous fermentation.

\section{Acknowledgements}

The authors would like to thank the German Science Foundation for financial support (Ko 785/17-1), and Christiane Grünewald and Armin Gneipel for their technical assistance.

\section{References}

Almeida, P., Gonçalves, C., Teixeira, S., Libkind, D., Bontrager, M., Masneuf, P., ... Sampaio, J. S. (2014). A Gondwanan imprint on global diversity and domestication of wine and cider yeast Saccharomyces uvarum. Nature Communications, 5, 4044. http://dx.doi.org/10.1038/ncomms5044

Arroyo-López, F. N., Orlić, S., Querol, A., \& Barrio, E. (2009). Effects of temperature, pH and sugar concentration on the growth parameters of Saccharomyces cerevisiae, S. kudriavzevii and their interspecific hybrid. International Journal of Food Microbiology, 131, 120-127. http://dx.doi.org/10.1016/j.ijfoodmicro.2009.01.035

Belloch, C., Orlic, S., Barrio, E., \& Querol, A. (2008). Fermentative stress adaptation of hybrids within the Saccharomyces sensu stricto complex. International Journal of Food Microbiology, 122, 188-195. http://dx.doi.org/10.1016/j.ijfoodmicro.2007.11.083

Bely, M., Sablayrolles, J. M., \& Barre, P. (1990). Automatic detection of assimilable nitrogen deficiences during alcoholic alcoholic fermentation in oenological conditions. Journal of Fermentation and Bioengineering, 70, 246-252. http://dx.doi.org/10.2016./0922-338X(90)90057-4

Berthels, N. J., Cordero Otero, R. R., Bauer, F. F., Pretorius, I. S., \& Thevelein, J. M. (2008). Correlation between glucose/ fructose discrepancy and hexokinase kinetic properties in different Saccharomyces cerevisiae wine yeast strains. Applied Microbiology and Biotechnology, 77, 1083-1091. http://dx.doi.org/10.1007/s00253-007-1231-2

Berthels, N. J., Otero, R. R. C., Bauer, F. F., Thevelein, J. M., \& Pretorius, I. S. (2004). Discrepancy in glucose und fructose utilization during fermentation by Saccharomyces cerevisiae wine yeast strains. FEMS Yeast Research, 4, 683-689. http://dx.doi.org/10.1016/j.femsyr.2004.02.005

Bisson, L. F. (1999). Stuck and sluggish fermentations. American Journal of Enology and Viticulture, 50, 107-119.

Blättel, V. (2012). Identifizierung, Quantifizierung und Hemmung von ausgewählten Hefen in Wein [Identification, quantification and inhibition of selected yeasts in wine] (Dissertation). Johannes Gutenberg-Universität Mainz, Germany.

Blättel, V., Petri, A., Rabenstein, A., Kuever, J., \& König, H. (2013). Differentiation of species of the genus Saccharomyces using biomolecular fingerprinting methods. Applied Microbiology and Biotechnology, 97, 4597-4606. http://dx.doi.org/10.1007/s00253-013-4823-z

Boynton, P. J., \& Greig, D. (2014). The ecology and evolution of non-domesticated Saccharomyces species. Yeast, 31, 449-462. http://dx.doi.org/10.1002/yea.3040

Bradbury, J., Richards, K., Niederer, H., Lee, S., Rod Dunbar, P., \& Gardner, R. (2006). A homozygous diploid subset of commercial wine yeast strains. Antonie van Leeuwenhoek, 89, 27-37. 
http://dx.doi.org/10.1007/s10482-005-9006-1

Dickinson, F. M., \& Dack, S. (2001). The activity of yeast ADH I and ADH II with long-chain alcohols and diols. Chemico-Biological Interactions, 130-132, 417-423. http://dx.doi.org/10.1016/S0009-2797(00)00266-0

Dittrich, H. H., \& Großmann, M. (2005). Mikrobiologie des Weines. Ulmer Verlag, Stuttgart.

Divol, B., \& Lonvaud-Funel, A. (2005). Evidence for viable but nonculturable yeasts in Botrytis-affected wine. Journal of Applied Microbiology, 99, 85-93. http://dx.doi.org/10.1111/j.1365-2672.2005.02578.x

Fleet, G. H., \& Heard, G. M. (1993). Yeasts - growth during fermentation. In G. H. Fleet (Ed.), Wine microbiology and biotechnology (pp. 27-54). Harwood Academic Publishers GmbH, Chur.

Gafner, J., \& Schütz, M. (1993). Sluggish alcoholic fermentation in relation to alterations of the glucose-fructose ratio. Chemie, Mikrobiologie, Technologie der Lebensmittel, 15, 73-78.

González, S. S., Barrio, E., Gafner, J., \& Querol, A. (2006). Natural hybrids from Saccharomyces cerevisiae, Saccharomyces bayanus and Saccharomyces kudriavzevii in wine fermentations. FEMS Yeast Research, 6, 1221-1234. http://dx.doi.org/10.1111/j.1567-1364.2006.00126.x

González, S. S., Barrio, E., \& Querol, A. (2008). Molecular characterization of new natural hybrids between Saccharomyces cerevisiae and Saccharomyces kudriavzevii from brewing. Applied and Environmental Microbiology, 74, 2314-2320. http://dx.doi.org/10.1128/AEM.01867.07

Heerde, E., \& Radler, F. (1978). Metabolism of the anaerobic formation of succinic acid by Saccharomyces cerevisiae. Archives of Microbiology, 117, 269-276. http://dx.doi.org/10.1007/BF00738546

Jiranek, V., Langridge, P., \& Henschke, P. A. (1995). Amino acid and ammonium utilization by Saccharomyces cerevisiae wine yeasts from a chemically defined medium. American Journal of Enology and Viticulture, 46, 75-83.

Lomolino, G., Lante, A., Crapisi, A., Spettoli, P., \& Curioni, A. (2001). Detection of Saccharomyces cerevisiae carboxylesterase activity after native and sodium dodecyl sulfate electrophoresis by using fluorescein diacetate as substrate. Electrophoresis, 22, 1021-1023. http://dx.doi.org/10.1002/1522-2683()22:6<1021::A ID-ELPS1021>3.0.CO;2-B

Lopes, C. A., Barrio, E., \& Querol, A. (2010). Natural hybrids of $S$. cerevisiae $\times S$. kudriavzevii share alleles with European wild populations of Saccharomyces kudriavzevii. FEMS Yeast Research, 10, $412-421$. http://dx.doi.org/10.1111/j.1567-1364.2010.00614.x

Mateo, J.J. \& Di Stefano, R., (1997). Description of the $\beta$-glucosidase activity of wine yeasts. Food Microbiology, 14, 583-591. http://dx.doi.org/10.1006/fmic.1997.0122

Naumov, G. I., James, S. A., Naumova, E. S., Louis, E. J., \& Roberts, I. N. (2000). Three new species in the Saccharomyces sensu stricto complex: Saccharomyces cariocanus, Saccharomyces kudriavzevii and Saccharomyces mikatae. International Journal of Systematic and Evolutionary Microbiology, 50, 1931-1942, http://dx.doi.org/10.1099/00207713-50-5-1931

Peris, D., Lopes, C. A., Arias, A., \& Barrio, E. (2012). Reconstruction of the evolutionary history of Saccharomyces cerevisiae $\times$ S. kudriavzevii hybrids based on multilocus sequence analysis. PLoS One, 7(9), e45527. http://dx.doi.org/10.1371/journal.pone.0045527

Pfeiffer, P., \& Radler, F. (1985). Hochleistungsflüssigchromatographische Bestimmung von organischen Säuren, Zuckern, Glycerin und Alkohol im Wein an einer Kationenaustauschersäule [High-performance liquid chromatographic determination of organic acids, sugars, glycerol and alcohol in wine by a cation exchange]. Zeitschrift für Lebensmittel-Untersuchung und-Forschung, 181, 24-27. http://dx.doi.org/10.1007/BF011248 02

Pretorius, I. S. (2000). Tailoring wine yeast for the new millenium: Novel approaches to the ancient art of winemaking. Yeast, 16, 675-729. http://dx.doi.org/10.1002/1097-0061(20000615)16:8<675::AID-YEA585> 3.0.CO;2-B

Salvadó, Z., Arroyo-López, F. N., Guillamón, J. M., Salazar, G., Querol, A., \& Barrio, E. (2011). Temperature adaptation markedly determines the growth and evolution within the genus Saccharomyces. Applied and Environmental Microbiology, 77, 2292-2302. http://dx.doi.org/10.1128/AEM.01861-10

Sampaio, J. P., \& Gonçalves, P. (2008). Natural populations of Saccharomyces kudriavzevii in Portugal are associated with oak bark and sympatric with $S$. cerevisiae and S. paradoxus. Applied and Environmental 
Microbiology, 74, 2144-2152. http://dx.doi.org/10.1128/AEM.02396-07

Serra, A., Strehaiano, P., \& Taillandier, P. (2005). Influence of temperature and pH on Saccharomyces bayanus var. uvarum growth; Impact of a wine yeast interspecific hybridization on these parameters. International Journal of Food Microbiology, 104, 257-265. http://dx.doi.org/10.1016/j.ijfoodmicro.2005.03.006

Tronchoni, J., Gamero, A., Arroyo-López, F. N., Barrio, E., \& Querol, A. (2009). Differences in the glucose and fructose consumption profiles in diverse Saccharomyces wine species and their hybrids during grape juice fermentation. International Journal of Food Microbiology, 134, 237-243, http://dx.doi.org/10.1016/j.ijfoodmicro.2009.07.004

Ultee, A., Wacker, A., Kunz, D., Löwenstein, R., \& König, H. (2013). Microbial succession in spontaneously fermented grape must before, during and after stuck fermentation. South African Journal of Enology and Viticulture, 34, 68-78.

Walsh, M. C., Smits, H. P., Scholte, M., \& van Dam, K. (1994). Affinity of glucose transport in Saccharomyces cerevisiae is modulated during growth on glucose. Journal of Bacteriology, 176, 953-958.

White, T. J., Bruns, T., Lee, S., \& Taylor, J. (1990). Amplification and direct sequencing of fungal ribosomal RNA genes for phylogenetics. In M. A. Innis, D. H. Gelfand, J. J. Sninsky \& T. J. White (Eds.), PCR protocols: A guide to methods and applications (pp. 315-322). Academic Press, Inc., New York. http://dx.doi.org/10.1016/B978-0-12-372180-8.50042-1

\section{Copyrights}

Copyright for this article is retained by the author(s), with first publication rights granted to the journal.

This is an open-access article distributed under the terms and conditions of the Creative Commons Attribution license (http://creativecommons.org/licenses/by/3.0/). 